\title{
A CHART FOR TESTING THE VISUAL ACUITY OF AMBLYOPIC CHILDREN AND ADULTS* $+\ddagger$
}

BY

ConRad Berens, M.D.

NEW YORK, N.Y.

THE need of a chart containing figures as well as letter $E$ 's to test highly amblyopic children and adults prompted the drawing of this chart. The chart is especially valuable in testing children of three years of age or younger, because they can easily recognise the figures.

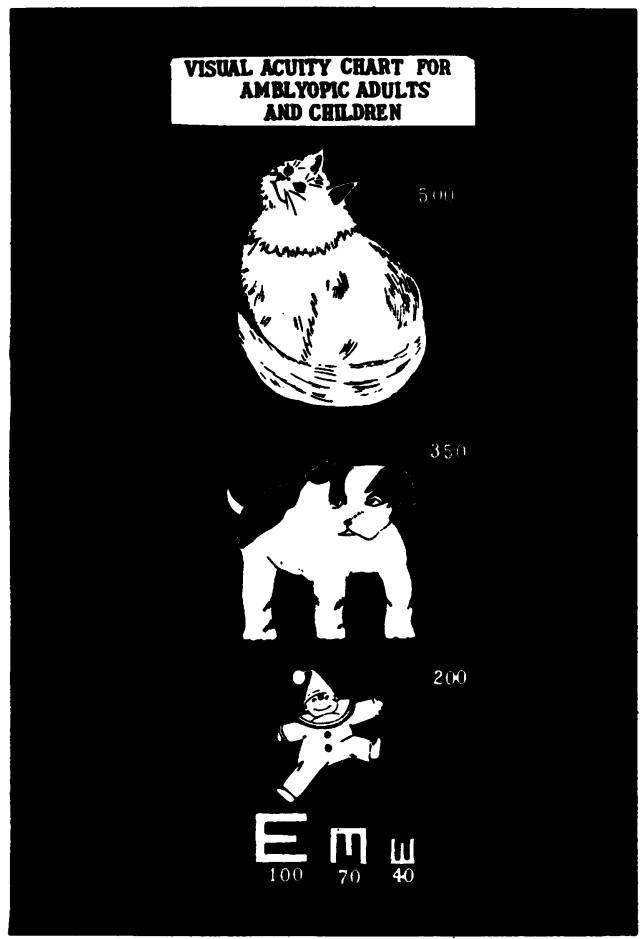

FIG. 1.
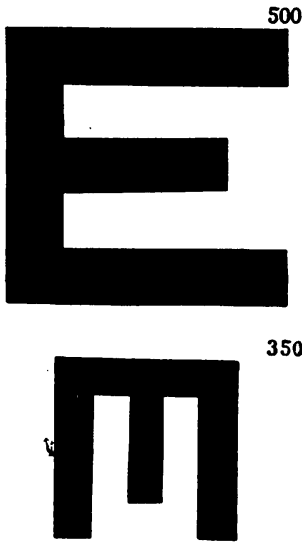

350

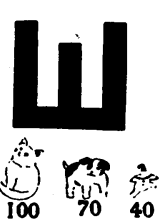

FIG. 2.

Back view of the chart.

Front view of the chart for testing the visual acuity of amblyopic children and adults.

* Presented before the Section on Ophthalmology of the American Medical Association, June 7-11, 1937, Atlantic City, New Jersey.

† Aided by a grant from the Ophthalmological Foundation, Inc., and developed with the co-operation of the Department of Motor Anomalies of the New York Eye and Ear Infirmary.

$\ddagger$ Drawings by Miss Patricia Rainier. 
The following figures have been used: a cat, 500 foot $(152.40$ M.); a dog, 350 foot (106.68 M.); and a clown, 200 foot (60.96 M.).

As an additional and possibly more scientific test 500 foot, 350 foot, and 200 foot $E$ 's appear on the reverse side of the chart

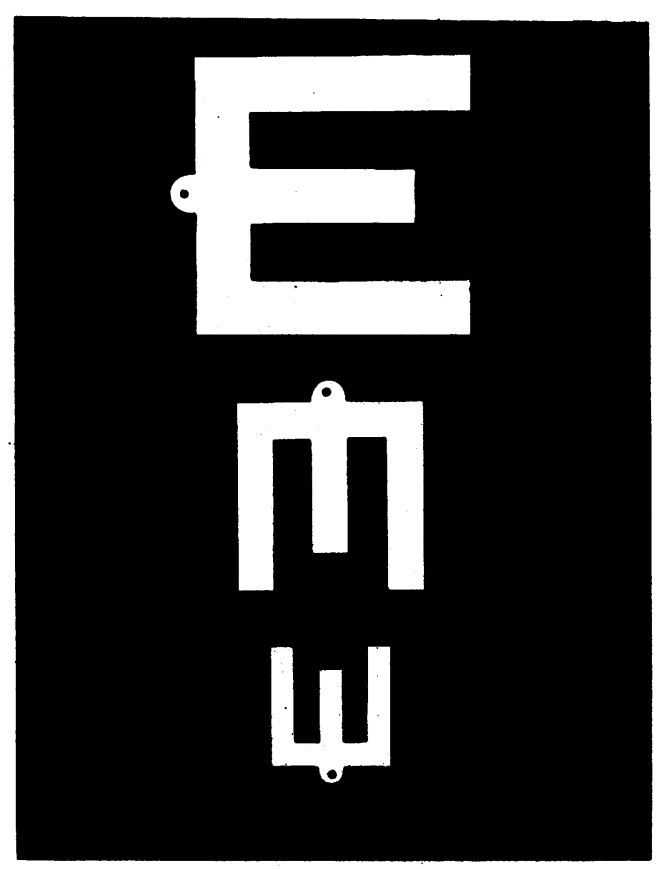

FIG. 3

Metal "E's."

(Figs. 1 and 2). In order to test the child's knowledge as well as visual acuity smaller drawings of the cat (100 feet, $30.48 \mathrm{M}$.), dog (70 feet, 21.33 M.), and clown (40 feet, 12.19 M.), are included in the chart. Furthermore, $E$ 's have also been placed beside these figures.

To facilitate the testing of visual acuity, especially for the use of children, each chart is supplied with 500 foot, 350 foot and 200 foot detachable $E$ 's which are made of metal (Fig. 3). 